\title{
ESTUDO DA PERCEPÇÃO DA INTENSIDADE SONORA NO ENSINO DE CIÊNCIAS
}

\author{
Andréa Magale Berro Vernier ${ }^{1}$ \\ Carlos Maximiliano Dutra ${ }^{2}$ \\ Émerson Juliano dos Santos Silva ${ }^{3}$
}

\begin{abstract}
Resumo: A Base Nacional Comum Curricular na área de Ciências para o $9^{\circ}$ ano do Ensino Fundamental propóe dentre vários temas o estudo do Som. No presente trabalho apresentamos uma abordagem contextualizada e prática do estudo da intensidade sonora através da aplicação de um questionário de avaliação da "Atitude dos jovens frente ao ruído" e da medição da intensidade sonora através do aplicativo de celular "Sound Meter". Essas atividades foram realizadas no âmbito escolar junto a um grupo de estudantes de uma escola estadual de Uruguaiana/RS. Dos resultados dos questionários destacamos que os estudantes identificam a perturbação causada por ruídos sonoros externos no desenvolvimento das aulas e se preocupam em manter um ambiente sonoro agradável no ambiente escolar. Foram mensurados pelos estudantes valores de intensidade sonora de 61 a 64 $\mathrm{dB}$ em média, valores que estão acima do intervalo estabelecido pela legislaçáo para sala de aula. As atividades permitiram aos alunos momentos de discussão e mensuração da intensidade sonora nas diferentes atividades realizadas no dia-a-dia do estudante, sobretudo no cotidiano escolar; e como a exposição a intensidade sonora além da permitida coloca a saúde em risco.
\end{abstract}

Palavras-chave: ensino ciências; experimentação; som; aplicativo móvel.

\section{STUDY OF PERCEPTION OF SOUND INTENSITY IN SCIENCE TEACHING}

Abstract: The Common National Curricular Base in the Science area for the 9th year of Elementary Education proposes, among several themes, the study of Sound. In the present work we present

1 Doutoranda de Educação em Ciências: Química da Vida e Saúde. Universidade Federal do Pampa - UNIPAMPA. E-mail: andreiaberro34@gmail.com

2 Doutor em Ciências (UFRGS). Professor na Universidade Federal do Pampa - UNIPAMPA. E-mail: profcarlosmaxdutra@gmail.com

3 Licenciado em Ciências da Natureza (UNIPAMPA). Professor de Ciências na Educação Básica. E-mail: emersonjssilva@gmail.com 
a contextualized and practical approach to the study of sound intensity through the application of a questionnaire to evaluate the "Attitude" of young people facing noise "and the measurement of sound intensity through the mobile app" Sound Meter ". These activities were carried out at school with a group of students from a state school in Uruguaiana / RS. From the results of the questionnaires we highlight that the students identify the disturbance caused by external sound noises in the development of the classes and worry about maintaining a pleasant sound environment in the school environment. Sound intensity values from 61 to $64 \mathrm{~dB}$ on average were measured by the students, values that are above the interval established by the legislation for the classroom. The activities allowed an important reflection on the daily habits of the school and how they interfere with the sound intensity, putting health at risk.

Keywords: science teaching; experimentation; sound; mobile app

\section{Introduçáo}

Segundo Sirvinskas (2018) o som constitui um fenômeno acústico dado pela propagação de ondas sonoras produzidas por um corpo que vibra em meio material, como por exemplo, no ar onde produz zonas de compressão e rarefação. Segundo Usberco et al (2015) as ondas sonoras percebidas pelo tímpano humano variam em uma frequência de $20 \mathrm{~Hz}$ a $20000 \mathrm{~Hz}$, e a essa sensação auditiva atribui-se o nome de som. Ainda segundo o autor, pela percepçáo auditiva do ouvido humano distinguem-se 3 faixas de altura sonora (associada a frequência): $20-500 \mathrm{~Hz}$ (sons graves); $500 \mathrm{~Hz}$ a $4 \mathrm{kHz}$ (sons médios) e $4 \mathrm{kHz}$ a $20 \mathrm{Khz}$ (sons agudos). Ainda segundo o autor cabe distinguir o som que é natural, harmonioso e agradável do ruído que consiste em um som desordenado, estrondoso e desagradável. Tanto o som como principalmente os ruídos podem causar desconforto quando ultrapassam determinados limites de intensidade. Segundo Bressane (2010) a intensidade do som, ou o nível sonoro, ou nível de ruído, é medido em decibéis (dB) formada por uma razão do som/ruído de medida em relação a uma referência, obedecendo uma sensibilidade de percepção que segue uma escala logarítmica. Os instrumentos utilizados para medição de intensidade sonora são chamados de decibelímetros.

A Associação Brasileira de Normas Técnicas (ABNT) é responsável por estabelecer normas de medição e limites para os níveis de pressão sonora em áreas habitadas NBR 10.151/2000 (com valores desde máximos de 40dB em áreas de sítios e fazendas; $55 \mathrm{~dB}$ em áreas residenciais à $70 \mathrm{~dB}$ em área predominantemente industrial) e também estabelece na NBR 10.152/1987 que fixa níveis de ruído compatíveis com o conforto acústico em diversos ambientes tais como: hospitais, escolas (destacando o estabelecimento de limites de 34-45 dB nas bibliotecas; 40$50 \mathrm{~dB}$ nas salas de aula e laboratórios; e $45-55 \mathrm{~dB}$ nos ambientes de circulação), hotéis, residências, dentre outros. O Ministério do Trabalho também por normativa estabelece através da Norma Regulamentadora no 15 - "Atividades e Operaçóes Insalubres - Anexo 1" os limites do nível de pressáo sonora máximo permitido de acordo com o tempo de exposição ao som que varia de $85 \mathrm{~dB}$ ao longo de $8 \mathrm{~h}$ até o ruído máximo de $115 \mathrm{~dB}$ por 7 minutos, sendo proibida a exposição a ruídos acima de $115 \mathrm{~dB}$ sem a devida proteçáo. A Organização Pan-Americana de Saúde (OPAS, 1983) estabelece que ruídos acima de $85 \mathrm{~dB}$ são nocivos à saúde dos indivíduos. 
Conforme a resolução 001/1990 do CONAMA os problemas dos níveis excessivos de ruído constituem em poluição do Meio Ambiente, a poluiçáo sonora, que necessita de normativa de controle para não prejudicar a saúde e o sossego público. A resolução 272/2000 do CONAMA define os limites máximos de ruídos para os veículos nacionais e importados em aceleração onde veículos de passageiros tem limite de nível de ruído em $74 \mathrm{~dB}$ e veículos de carga no máximo de $80 \mathrm{~dB}$. $\mathrm{Na}$ resolução 002/1990 do CONAMA é estabelecida uma Política Nacional de Educação e Controle da Poluiçáo Sonora intitulada "SILÊNCIO" onde dentre os seus objetivos destaca-se que deve ser abortado o tema de poluição sonora na rede de ensino através de um Programa de Educação Nacional. Tomé et al. (2018) destacam que a perda auditiva induzida pelo ruído (PAIR) provoca danos significativos na saúde dos jovens, como perda da sensibilidade auditiva e o aparecimento de zumbido, antes mesmo de provocar alguma perda auditiva perceptível, reiteram também a necessidade da elaboração de açóes no sentido de conscientizar sobre a importância de se preservar a saúde auditiva.

Palácios e Marqueze (2006) indicam que o uso de equipamentos de sons portáteis a $65 \%$ de capacidade podem dependendo do modelo gerar som de intensidade sonora da ordem de $85 \mathrm{~dB}$, com máximo em torno de $114 \mathrm{~dB}$; demonstrando que esa prática como entre os jovens pode promover com o tempo danos no aparelho auditivo. Segundo Barcelos e Dazzi (2014) alguns modelos de fones de ouvido, por serem inseridos no interior do Meato auditivo externo, acabam por potencializar os sons uma vez que deixam a fonte emissora da vibração muito próxima do tímpano, sendo com isso, mais prejudiciais que os fones externos, destaca-se também que o tempo de exposiçáo maximiza os perigos, visto que os dispositivos portáteis como celulares, que são os mais recorrentes junto aos jovens como mecanismos de execução musical, na atualidade dispóe de baterias que chegam a durar cerca de $24 \mathrm{~h}$.

A Base Nacional Comum Curricular (BNCC) prevê a temática do som para o $9^{\circ}$ ano no eixo temático Matéria e Energia "(EF09CI05) Investigar os principais mecanismos envolvidos na transmissáo e recepção de imagem e som que revolucionaram os sistemas de comunicação humana” (BNCC, 2017). Além disso, a BNCC aponta que o ensino de Ciências deve proporcionar aos estudantes situaçóes nas quais possam:

Desenvolver e utilizar ferramentas, inclusive digitais, para coleta, análise e representação de dados (imagens, esquemas, tabelas, gráficos, quadros, diagramas, mapas, modelos, representaçôes de sistemas, fluxogramas, mapas conceituais, simulaçóes, aplicativos etc) (BNCC, 2017 p.323).

A experimentação é um recurso didático que é implementado nas Escolas de acordo com a infraestrutura (laboratórios e insumos) e com a disponibilidade e formação do professor (Traversi et al. 2019). O uso das Tecnologias da Informação e Comunicação na Educação em especial, o uso de aplicativos de celular no ensino tem se constituido em um objeto de estudo no Ensino de Ciências, Silva (2018) 
fez um levantamento e analisou 42 aplicativos de celular potencialmente utilizáveis nessa área de ensino.

Lacerda et al. (2011) destaca a necessidade da conscientizaçáo dos jovens em relação aos seus hábitos e a exposição a poluição sonora. O presente trabalho constitui-se de um relato de experiência de uma nova estratégia de ensino para a abordagem prática e contextualizada do estudo da temática "Som", sobretudo a "Intensidade Sonora".

\section{Metodologia}

A estratégia de ensino baseia-se em duas atividades: (i) sensibilização sobre a presença do som na vida cotidiana dos estudantes e as atitudes dos mesmos em relação ao som; (ii) a medição da intensidade sonora no ambiente escolar.

Com a finalidade de mapear as percepçóes dos estudantes sobre a temática do Som; da Poluição sonora e Saúde Auditiva, propóe-se a aplicação do questionário "Atitudes da Juventude frente ao Ruído" (Quadro 1) de Zocolli et al. (2009), que adaptou e validou o questionário "Youth Attitude to Noise Scale" - YANS. O Quadro 1 que consta em sua parte superior de duas colunas, uma com a indicação das afirmativas e a segunda com as alternativas numerada de 1 a 5 . Estas indicam o grau de concordância do estudante em relação às afirmaçóes, considerando o número 1 para o menor grau de concordância e 5 para o maior grau de concordância, na primeira coluna vertical temos as 19 afirmativas, os estudantes devem ser orientados a marcar como resposta uma única alternativa para cada questão. Essas 19 questóes segundo Zocolli et al. (2009) podem ser agrupadas em 4 fatores de atitudes frente ao ruído sonoro: (i) Fator 1: Atitudes para o ruído associado com os aspectos da cultura da juventude (questóes 1, 4, 9, 10, 12, 15 e 18); (ii) Fator 2 : Atitudes para ruídos do dia-a-dia (questôes 11, 14, 16, 17 e 19); (iii) Fator 3: Atitudes para a habilidade de se concentrar em ambientes ruidosos (questóes 2, 5, 8 e 13); (iv) Fator 4: Atitudes para influenciar o ambiente sonoro (questôes 6, 7 e 3).

Quadro 1 - Questionário de avaliação da percepção sonora

\begin{tabular}{|c|c|c|c|c|c|}
\hline \multirow{2}{*}{ Questôes } & \multicolumn{5}{|c|}{ Alternativas } \\
\hline & 1 & 2 & 3 & 4 & 5 \\
\hline $\begin{array}{l}\text { 1.Eu acho que o volume do som nas discotecas, bailes, shows de rock e } \\
\text { eventos esportivos, em geral, é alto demais. }\end{array}$ & & & & & \\
\hline 2. Ouvir música enquanto faço tarefa escolar ajuda a me concentrar. & & & & & \\
\hline $\begin{array}{l}\text { 3. Estou preparado para fazer algo que torne o ambiente escolar mais } \\
\text { silencioso. }\end{array}$ & & & & & \\
\hline $\begin{array}{l}\text { 4. Quando o nível de som está muito alto, eu considero a possibilidade de sair } \\
\text { de uma discoteca, show de rock, baile ou evento esportivo. }\end{array}$ & & & & & \\
\hline 5. Consigo me concentrar mesmo se há muitos sons diferentes à minha volta. & & & & & \\
\hline $\begin{array}{l}\text { 6. Acho desnecessário utilizar protetor auditivo quando estou numa } \\
\text { discoteca, show de rock, baile ou evento esportivo. }\end{array}$ & & & & & \\
\hline
\end{tabular}




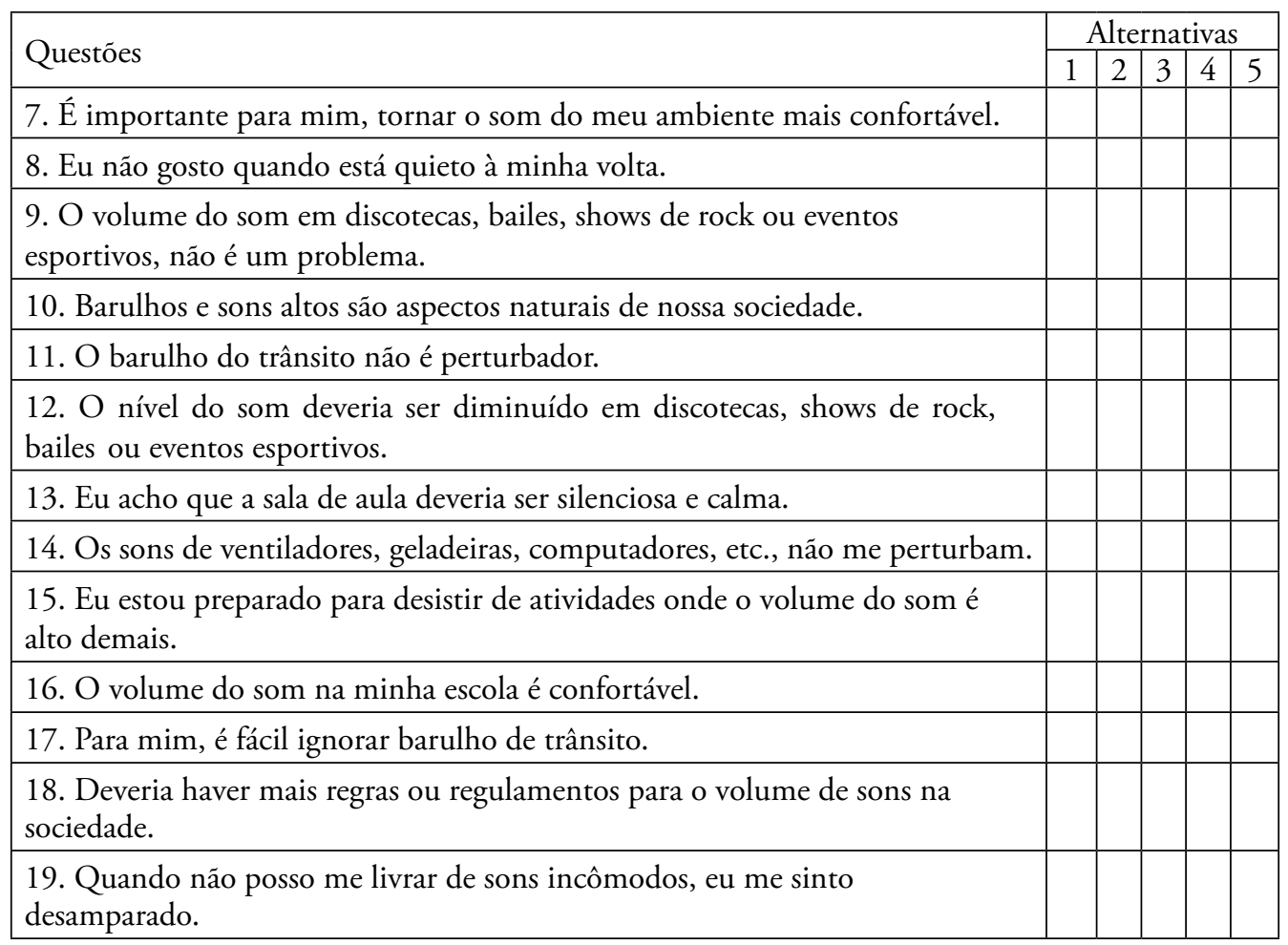

Fonte: ZOCOLLI et al. 2009

Após os alunos responderem os questionários, pode-se discutir se o nível de intensidade sonora que eles percebem nas diferentes situaçóes no dia-a-dia em casa, na escola e nas atividades de lazer trazem incômodo ou não; solicitando que eles dêem exemplos dessas situaçáo e citem as atitudes que tomam para superar esse incômodo, quando possível minimizá-lo. A partir dessas situaçôes reais de percepção da intensidade sonora trabalhar de que forma esta característica pode ser medida e abordar os instrumentos utilizados para essa mensuração e que permitem quantificar as diferentes atividades presentes na vida cotidiana com a construção de uma escala de nível de intensidade sonora. Em seguida aborda-se os limites de níveis de intensidade sonora permitidos pela legislaçáo para que o som náo se torne uma poluição sonora, que pode trazer danos a audiçáo.

A realização de atividades práticas de medição da intensidade sonora oportuniza aos estudantes estabelecer conexão entre a teoria e a prática, nesse sentido propomos a utilização de um aplicativo decibelimetro disponível para celulares. Existem diferentes aplicativos de celular que medem a intensidade sonora, sendo o mais adequado na nossa avaliação é o aplicativo decibelímetro "Sound Meter” (Figura 1), disponível no Google Play <https://play.google.com/store/apps/ details?id=com.best.code1979. . oundmeter $>$, que usa o sistema de som do aparelho celular como detector da intensidade sonora. O "Sound Meter" mostrou-se o mais adequado porque apresenta escala de níveis de intensidade sonora e todo o menu 
em português, apresenta mostrador digital da intensidade sonora, é gratuito; e além dessas características, a que se mostrou mais importante é que este aplicativo não perde a calibração quando o usuário sai do aplicativo. Cada aparelho de celular tem diferente grau de sensibilidade em relação ao som de forma que os valores podem diferir de um aparelho para outro em uma mesma situação e é necessário o processo de calibração para que em uma mesma situação todos meçam um mesmo valor e um valor compatível com a escala de intensidade sonora do aplicativo para uma determinada situação real proposta. Portanto após a aplicação do questionário de percepção sonora com a discussão de situaçôes de exposição ao som e a abordagem teórica da intensidade sonora, o professor deve solicitar aos alunos fazerem como lição de casa a instalação do aplicativo "Sound Meter" e fazer uma breve explicação sobre as telas do aplicativo.

No aplicativo em questão as intensidades são apresentadas na forma digital e expressas na escala de decibéis $(\mathrm{dB})$ com três opçóes de registros: (1) valor atual (no visor principal); (2) valor MIN ( primeiro valor abaixo do visor), representando o menor valor no intervalo de tempo da aquisição de valores de medida; (3) valor AVG (valor do meio dos valores apresentados abaixo do visor), representando o valor médio no intervalo de tempo de leitura; (4) valor MAX (terceiro e último valor apresentado abaixo do visor), representando o valor máximo no intervalo de tempo de leitura. No visor principal, além do valor atual de intensidade sonora apresentado em forma digital tem-se no canto superior esquerdo o tempo transcorrido da medição e abaixo da intensidade a classificação do valor de intensidade sonora atual em relação a uma Escala de Intensidade Sonora relacionada ao Cotidiano que é apresentada na Figura 2. A direita do visor principal temos dois ícones: o ícone com uma lâmpada que controla de claridade da tela; e por fim o ícone com a câmera que permite fazer print da tela. 
Figura 1- Imagem do aplicativo

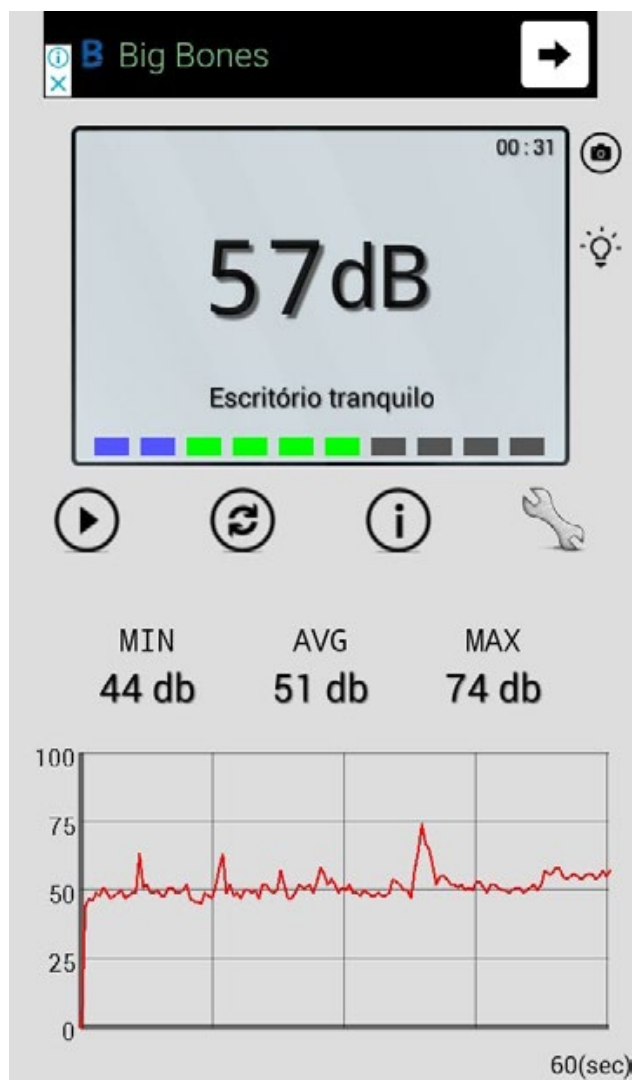

Fonte: Disponível em Play https://play.google.com/store/apps/details?id=com.best.code1979. soundmeter. Acesso em: 24/10/2019.

Abaixo do visor principal temos quatro ícones: no ícone "chave de fenda" temos a função de calibração, onde podemos calibrar a precisão de leitura de acordo com a sensibilidade do microfone do celular; na sequência temos um ícone com a letra "i" que se refere a dados de escala comparativa das intensidades de som medidas com níveis de ruído de situaçóes pré-definidas e conhecidas (conforme Figura 2); seguindo temos o ícone de atualização para reinicializar as mediçóes; e finalizando o ícone de "play/pause" para iniciar/pausar as mediçôes.

No final da tela do aplicativo (conforme Figura 1), temos um gráfico onde no eixo x é indicado o tempo em intervalos de 60 segundos e no eixo y é indicada a intensidade sonora em $\mathrm{dB}$ em intervalos de $25 \mathrm{~dB}$ indo de $0 \mathrm{~dB}$ até $100 \mathrm{~dB}$ 
Figura 2 - Escala comparativa entre a intensidade do som aferido pelo aplicativo e situaçóes

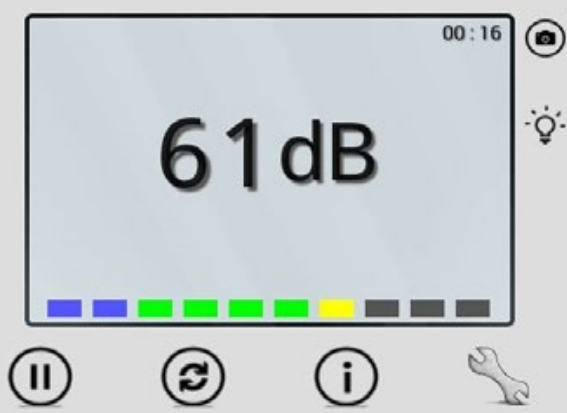

Ruído média :

$\begin{array}{lr}\text { No limite da dor, Trovão } & 120 \mathrm{~dB} \\ \text { Rock, Criança a chorar } & 110 \mathrm{~dB} \\ \text { Metrô, Secador de cabelo } & 100 \mathrm{~dB} \\ \text { Máquinas de uma fábrica } & 90 \mathrm{~dB} \\ \text { Rua movimentada, Alarme } & 80 \mathrm{~dB} \\ \text { Tráfego local, Toque de telefone } & 70 \mathrm{~dB} \\ \text { Conversação normal } & 60 \mathrm{~dB} \\ \text { Escritório tranquilo, Rua tranquila } & 50 \mathrm{~dB} \\ \text { Área residencial silenciosa, Parque } & 40 \mathrm{~dB} \\ \text { Sussurro, Biblioteca } & 30 \mathrm{~dB} \\ \text { Folhas ao vento, Tic tac do Relógio } & 20 \mathrm{~dB}\end{array}$

Fonte: Disponível em: Play https://play.google.com/store/apps/details?id=com.best.code1979. soundmeter. Acesso em: 24/10/2019.

No segundo encontro, os estudantes recebem uma devolutiva das respostas do questionário de percepção sonora, através da exibição de gráfico com o resultado do Ranking Médio considerando o valor atribuído a cada resposta de cada aluno, baseada na escala de Likert e o número de alunos que responderam o item. $\mathrm{Na}$ sequência buscando estabelecer reflexôes a cerca dos dados apresentados, pode-se discutir o grau de concordância de cada questão com a manifestação de alunos com alto e baixo grau de concordância expondo suas razóes para tal resposta em cada questão.

Concluídas as reflexóes propóe-se o acompanhamento dos níveis de intensidade sonora no ambiente escolar. Onde o professor então retomará o aplicativo decibelímetro explicando o funcionamento e realizando com os alunos o procedimento de calibração necessário antes das mediçôes, para dessa forma terem o mesmo valor de referência de intensidade sonora para um mesmo ruído e essa medida compatível com a escala de intensidade sonora do aplicativo. Nesse sentido o professor deve previamente em casa utilizar o aplicativo fazendo a mediçáo em um local silencioso que caracterize como "Sussurro, biblioteca" e utilizando o ícone "chave de fenda" fazer a medida atual (indicada no visor principal) coincidir com 
$30 \mathrm{~dB}$ usando os sinais de “+” e "-“" até alcançar esse valor, desse modo o aplicativo do professor estará calibrado.

Convém notar que não trabalhamos com os valores médios AVG porque são influenciados pelos baixos valores de logo quando ligamos o aplicativo, bem como por variaçóes abruptas de ruído que ocorram durante o processo de medida. No início da aula de mediçáo o professor deve solicitar para que os alunos coloquem o aplicativo nos celulares e que levem até a classe do professor, o professor coloca então o aplicativo no seu celular e realiza uma mediçáo da intensidade sonora atual (visor principal) após 30 segundos simultaneamente com os alunos e após darem "pause" ao final do tempo. Então para calibrar, cada aluno em seu celular deverá usar o ícone "chave de fenda" para fazer a medida atual coincidir com a leitura obtida no celular do professor usando os sinais de “+” e "_" até alcançar esse valor.

Para exemplificar, se após os 30 segundos o aplicativo do celular do professor (já calibrado) indicou $38 \mathrm{~dB}$, e o do aluno deu $40 \mathrm{~dB}$, ele deverá "subtrair" $2 \mathrm{~dB}$ das suas leituras, então deve ir no ícone "chave de fenda" colocar " 2 " e pressionar o ícone "-“. Por outro lado se o aplicativo do celular do professor indicou $38 \mathrm{~dB}$ e o do aluno marca $35 \mathrm{~dB}$, o mesmo deverá fazer o ajuste no ícone "chave de fenda" colocar " 3 " e pressionar o ícone "+". Ao final desse processo para um mesmo evento todos os aplicativos dos diferentes celulares estaráo indicando o mesmo valor.

Com os aplicativos dos celulares devidamente calibrados poderá ser realizada ao longo de um dia escolar a atividade de medição da intensidade do som. Deverá ser medida a intensidade sonora ao longo dos cinco períodos e intervalo, considerando uma turma típica composta por 30 estudantes, pode-se dividir em três subgrupos de 10 alunos que formaráo 5 duplas que faráo leituras do valor atual de intensidade sonora após 30 segundos de duração no $15^{\circ}$ minuto, no $30^{\circ}$ minuto e no $45^{\circ}$ minuto de cada um dos 5 períodos de 50 minutos ao longo de um dia de aula. Dessa forma para cada período teremos um total de 15 mediçóes de intensidade sonora de valores atuais (ou correntes) medidos ao final do $30^{\circ}$ segundo as quais permitiráo determinar os valores médios de intensidade atual em cada período. Cada dupla recebe uma folha para registro das mediçóes conforme o Quadro 2, indicando o subgrupo de medição, se realiza a medida no $15^{\circ}, 30^{\circ}$ ou $45^{\circ}$ minuto após o início da aula.

Considerando ainda que as Escolas dispóem geralmente 15 minutos de intervalo, os mesmos podem realizar mediçóes de valores de intensidade sonora "atual" no recreio considerando o quarto, oitavo e décimo segundo minuto do intervalo. Teríamos 5 duplas medindo em cada um desses intervalos totalizando 15 mediçóes ao longo do intervalo para cálculo do valor médio de intensidade no intervalo. Tendo em conta que a ideia principal é organizar o grupo de alunos de forma a ter um grupo de mediçóes em diferentes momentos ao longo dos períodos para poder estimar um valor médio, que represente o período todo de 50 minutos ( ou intervalo de 15 minutos) já que o tempo de aquisição de medida de intensidade no aplicativo é de 30 segundos, o professor pode adaptar essa atividade de medição de acordo com o número de alunos que dispor. 
Quadro 2- Dados de mediçáo de intensidade sonora em aula, por dupla

\begin{tabular}{|c|c|c|c|}
\hline SubGrupo & $\begin{array}{c}\text { () Período, } 15^{\circ} \text { min } \\
\text { ( ) intervalo } 4^{\circ}\end{array}$ & $\begin{array}{l}\text { () Período, } 30^{\circ} \text { min } \\
\text { () intervalo } 8^{\circ}\end{array}$ & $\begin{array}{c}\text { ( ) Período, } 45^{\circ} \text { min } \\
\text { ( ) intervalo } 12^{\circ}\end{array}$ \\
\hline Intensidade & ATUAL & ATUAL & ATUAL \\
\hline $1^{\circ}$ Período & & & \\
\hline $2^{\circ}$ Período & & & \\
\hline $3^{\circ}$ Período & & & \\
\hline Intervalo & & & \\
\hline $4^{\circ}$ Período & & & \\
\hline $5^{\circ}$ Período & & & \\
\hline
\end{tabular}

Fonte: Produzida pelos autores.

Posteriormente em um encontro de análise das medidas com o aplicativo decibelímetro "Sound Meter" o professor poderá reunir os grupos em sala de aula para o cálculo coletivo das médias de intensidade sonora nos diferentes momentos ao longo de um dia escolar ou apresentar em forma de tabela os resultados obtidos com as médias das mediçóes dos alunos durante os períodos e verificar junto com os alunos se os níveis de tolerância da legislação quanto a intensidade sonora são atendidos em sala de aula e no intervalo. Em sequência pode-se discutir com os alunos as medidas individuais e coletivas que poderiam ser tomadas para reduzir a intensidade sonora evitando a poluição se for o caso e pensar em estratégias de divulgar o trabalho junto a comunidade escolar e conscientizá-la sobre a importância de conhecer a temática para preservação da sáude auditiva.

\section{Aplicação e Resultados}

As atividades propostas na metodologia foram aplicadas em uma turma com 30 estudantes (com faixa etária de 13 a 16 anos) do $9^{\circ}$ ano do Ensino Fundamental de uma escola estadual da cidade de Uruguaiana-RS. A aplicação seguiu resumidamente as seguintes etapas, conforme a metodologia: etapa 1 aplicaçáo questionário Percepção Intensidade Sonora e breve discussão sobre a intensidade dos sons percebidos no dia-a-dia que serviu de introdução para abordagem teórica sobre a Intensidade Sonora, ao final foi proposto aos alunos a instalação nos seus celulares do aplicativo decibelímetro "Sound Meter"; etapa 2 apresentação dos resultados do questionário de Percepção Intensidade Sonora aos alunos com discussão a cerca dos baixos e altos graus de concordância em cada questão e explicação sobre o funcionamento do aplicativo "Sound Meter" agora já instalado nos celulares dos alunos sendo na sequência realizado o procedimento de calibração; etapa 3 - medição das intensidades sonoras com aplicativo durante um dia inteiro de aulas, foram formados os grupos conforme a afinidade dos alunos e também vizinhança de classes na sala de aula para facilitar as mediçóes e foi dada 
ciência e solicitada autorizaçáo dos professores dos cinco períodos para a realizaçáo das mediçóes durante as atividades de suas aulas, ao final do dia os registros das medições foram recolhidos para tabulação e cálculos; etapa 4 - apresentação dos resultados médios de intensidade sonora por periodo e no recreio e discussão dos resultados considerando a legislação.

A Figura 3 mostra os resultados obtidos da aplicaçáo do questionário de Percepçáo de Intensidade Sonora de Zocolli et al. (2009), onde para cada questáo foi calculado o Ranking Médio considerando o valor de cada resposta de cada aluno baseada na escala de Likert e o número de alunos que responderam o item. O gráfico dos resultados gerais da aplicaçáo do questionário (Figura 3) foi compartilhado com os estudantes, sendo conduzida discussão conforme a metodologia, ou seja discutir o grau de concordância nas questôes com estudantes que demonstraram baixa e alta concordância apresentando suas razóes. Não foram gravados posicionamentos já que a intenção da atividade era uma discussáo inicial e sensibilização em relação a percepção da intensidade sonora no cotidiano.

Figura 3 - Resultados aplicação questionário "Atitudes da Juventude frente ao Ruído" (Quadro 1) de Zocolli et al. (2009).

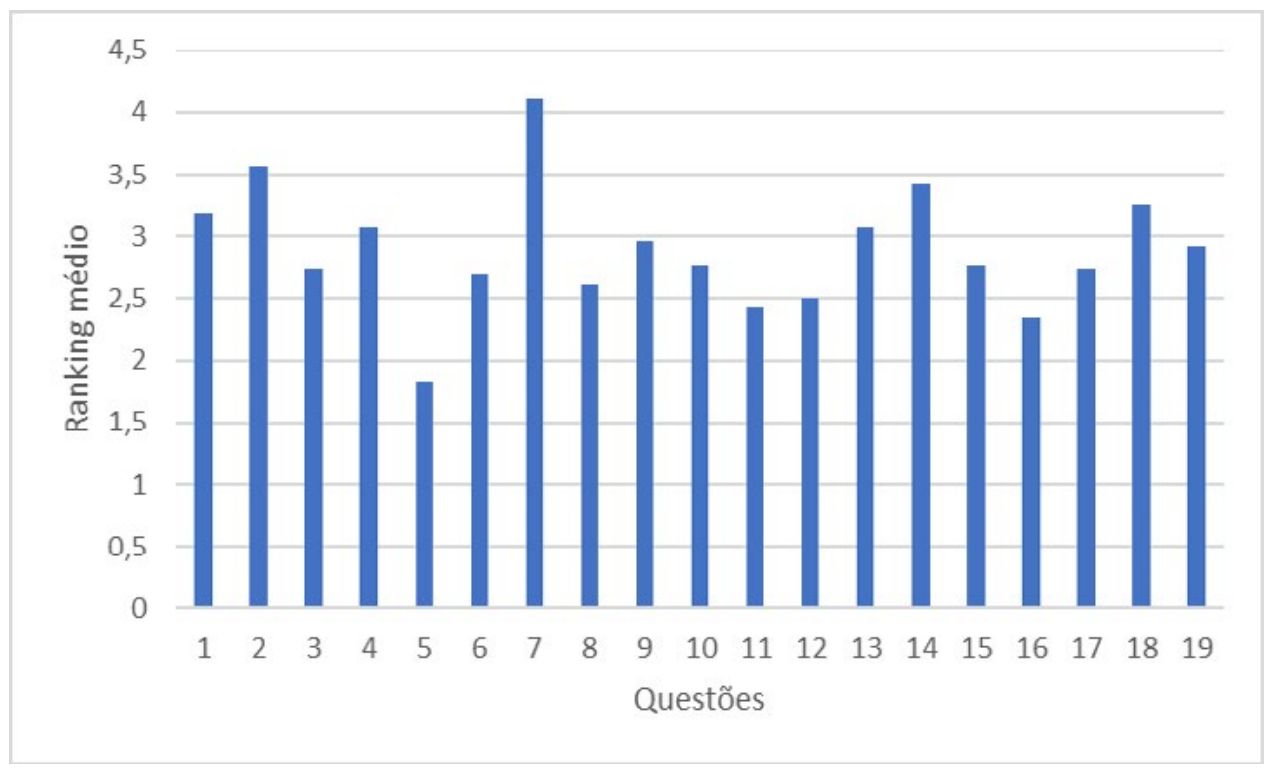

Fonte: Produzida pelos próprios autores.

Considerando os resultados diretos das respostas de todas as questôes apresentadas na Figura 3, obtém-se uma média de 2,89 com desvio padrão de 0,49 ; tendo em conta o grau de concordância em relação as questôes variando de 1 (menor) para 5 (maior) tivemos uma concordância intermediária similar à de Zocolli et al. (2009) que obteve 2,80 com desvio padrão de 1,31 para uma amostra de 245 alunos. Destacando que quanto mais próximo de 5 mais a atitude é considerada 
positiva frente a exposição de intensidade sonora nas diversas situaçóes. Percebemos pelo gráfico que em relação à questão 5 que os alunos denotam a atitude mais negativa indicando que os sons no seu entorno perturbam a concentração em aula; já a atitude mais positiva encontra-se na questão 7 demonstrando a preocupação em contribuir para a manutençáo de um nível de intensidade sonora agradável no ambiente.

Tendo em conta o agrupamento das questóes pelos fatores conforme Zocolli et al. (2009) para comparação, encontramos os seguintes resultados apresentados na Tabela 1. Os resultados obtidos no presente trabalho sáo comparáveis aos de Zocolli et al. (2009) destacando que neste temos uma amostra de 30 alunos de uma mesma série enquanto que Zocolli et al. (2009) teve amostra de 245 alunos do $1^{\circ}, 2^{\circ}$ e $3^{\circ}$ anos do Ensino Médio o que denota um espalhamento maior dos dados com valores mais altos de desvio padrão. A nossa amostra e a de Zocolli et al. (2009) tiveram valores bem próximos nos fatores 2 (Atitudes para ruídos do dia-a-dia) e 4 (Atitudes para influenciar o ambiente sonoro); por outro lado, enquanto que nossa amostra teve atitude mais positiva que a de Zocolli et al. (2009) no fator 1 (Atitudes para o ruído associado com os aspectos da cultura da juventude), a de Zocolli et al. (2009) demonstrou-se com atitude mais positiva no fator 3 (Atitudes para a habilidade de se concentrar em ambientes ruidosos) em relação a do presente trabalho.

Tabela 1: Comparaçáo dos resultados de Atitude frente ao ruído agrupada em fatores.

\begin{tabular}{|c|c|c|}
\hline Fator & $\begin{array}{c}\text { Média } \pm \text { DesvioPadrão } \\
\text { Zocolli et al. }(2009)\end{array}$ & $\begin{array}{c}\text { Média } \pm \text { DesvioPadrão } \\
\text { Presente trabalho }\end{array}$ \\
\hline 1 & $2,36 \pm 1,15$ & $2,93 \pm 0,25$ \\
\hline 2 & $2,76 \pm 1,29$ & $2,77 \pm 0,39$ \\
\hline 3 & $3,38 \pm 1,28$ & $2,77 \pm 0,63$ \\
\hline 4 & $3,13 \pm 1,37$ & $3,18 \pm 0,66$ \\
\hline
\end{tabular}

Fonte: Produzida pelos autores.

Diante da utilização do aplicativo decibelímetro "Sound Meter" e preenchimento do Quadro 2, que expressa a medida de intensidade sonora atual após 30 segundos dos momentos de início de cada mediçáo, nos diferentes momentos de cada um dos cinco períodos letivos, foi feita a compilação dos dados e a elaboraçáo das médias a partir dos registros dos estudantes. Para o cálculo da média e desvio padrão de cada período consideramos primeiro o cálculo da intensidade sonora atual média de cada um dos três momentos (tendo em conta as 5 mediçóes de grupos em cada momento), em seguida era calculada a média e o desvio padráo do período com base nos três valores médios correspondentes aos momentos de medida. Os resultados de média de Intensidade resultantes representam a medida de Intensidade Sonora ao longo dos Períodos/Intervalo e estáo expressos em decibéis no Quadro 3. Estes resultados foram apresentados aos alunos com uma análise do 
valores obtidos quanto a variação ao longo dos períodos, quanto a classificação na escala de nivel de intensidade sonora e quanto aos limites de tolerância da legislação.

Quadro 3- Média dos dados obtidos com a utilização do decibelímetro.

\begin{tabular}{|c|l|l|}
\hline Período/Medição & \multicolumn{2}{|l|}{ Intensidade Sonora Atual após 30s de medição } \\
\hline & Média $(\mathrm{dB})$ & Desvio Padrão $(\mathrm{dB})$ \\
\hline $1^{\mathrm{o}}$ & 63,42 & 4,09 \\
\hline $2^{\mathrm{o}}$ & 62,67 & 6,61 \\
\hline $3^{\mathrm{o}}$ & 61,13 & 6,94 \\
\hline Intervalo & 64,33 & 7,12 \\
\hline $4^{\mathrm{o}}$ & 63,87 & 6,80 \\
\hline $5^{\mathrm{o}}$ & 63,00 & 7,97 \\
\hline
\end{tabular}

Fonte: Produzida pelos autores.

Percebemos que a média de intensidade sonora na sala de aula decai no transcorrer do primeiro ao terceiro período, mas a dispersão medida pelo desvio padrão aumenta indicando uma maior amplitude de valores demonstrando a inquietação da turma aumentando. No intervalo obtém-se o maior valor de intensidade sonora média e também a maior medida de dispersão indicada pelo desvio padrão alto; após o retorno do recreio, percebe-se a diminuição da intensidade sonora média, mas o desvio padráo aumenta do quarto para o quinto período demonstrando a inquietação dos alunos no último período.

Destaca-se que os valores encontrados no Quadro 3 quando comparados a escala de intensidade sonora do próprio aplicativo correspondem a um nível de intensidade que está entre uma "conversação normal" (60dB) e o "tráfego local" $(70 \mathrm{~dB})$, que pode ser considerado um ruido médio. Já no intervalo foi observado valores de intensidade sonora máximos da ordem de $78 \mathrm{~dB}$ que segundo a escala já estaria próximo ao nível de ruído de uma "Rua movimentada, alarme", o qual já seria um nível de ruído alto.

Conforme a NBR 10.152/1987 temos fixados como níveis de ruído com conforto acústico para ambiente escolar como: (i) 34-45 dB nas bibliotecas; (ii) 40$50 \mathrm{~dB}$ nas salas de aula e laboratórios; e (iii) $45-55 \mathrm{~dB}$ nos ambientes de circulação. Percebemos que os valores obtidos em sala de aula e espaço de recreio/intervalo estão acima dos designados pela norma técnica, entretanto devemos ponderar que nossas medidas são obtidas através de um aplicativo de celular que em princípio não está calibrado de acordo com os procedimentos e nem tem a precisão de um decibelímetro profissional que segue as normas da NBR 10.152/1987 e outras relativas à medição da intensidade sonora. Embora não haja uma correlação exata entre os intervalos de valores da NBR 10.152/1987 e os obtidos com o aplicativo decibelímetro, as mediçóes apresentam coerência interna com a calibraçáo realizada 
e com a escala de intensidade sonora do aplicativo permitindo uma boa percepção do nível de intensidade sonora ao longo do dia-a-dia escolar.

\section{Consideraçóes finais}

O estudo do som é um dos temas a serem abordados em Ciências no 9o do Ensino Fundamental em Ciências de acordo com a Base Nacional Curricular Comum; ainda segundo o documento devem ser desenvolvidos os temas da área de ciência de forma contextualizada com o cotidiano e ao mesmo tempo com a proposição de atividades práticas para desenvolver nos estudantes o espírito científico. Nesse trabalho tivemos a proposição de duas atividades práticas envolvendo a temática do Som que foram aplicadas junto a uma turma de $9^{\circ}$ ano do ensino fundamental de uma escola em Uruguaiana/RS.

A atividade inicial de sensibilização foi a aplicação de um questionário de Percepção Sonora do cotidiano de jovens estudantes descrito em um artigo de revista especializada em Otorrinolaringologia onde é possível colocar os alunos a refletirem suas diferentes atividades no dia a dia e suas atitudes e sensaçóes em relação às diferentes intensidades sonoras dessas atividades. O questionário aborda questôes fechadas em escala graduada de concordância considerando afirmaçóes envolvendo situaçóes relacionadas a 4 fatores: (i) Fator 1: Atitudes para o ruído associado com os aspectos da cultura da juventude; (ii) Fator 2 : Atitudes para ruídos do dia-a-dia; (iii) Fator 3: Atitudes para a habilidade de se concentrar em ambientes ruidosos; (iv) Fator 4: Atitudes para influenciar o ambiente sonoro. Os resultados das respostas dos questionários foram discutidos com os alunos, destacamos que pelas respostas os alunos indicam a percepção de que os ruídos externos atrapalham na concentração em aula e que existe uma preocupação em que seja mantido um nível de intensidade sonora agradável no ambiente. Os resultados médios obtidos com a turma comparados com o do trabalho original de elaboração do questionário mostraram que a turma de alunos objeto desse trabalho teve comportamento semelhante as do artigo original nos fatores 2 e 4 . No fator 1 a presente turma de alunos demonstrou-se com sensibilidade maior aos sons altos de bailes e eventos culturais e esportivos; enquanto que no fator 3 a presente turma se sente menos capaz de manter concentraçáo e lidar com ambientes ruidosos.

A segunda atividade envolveu a medição da intensidade sonora utilizando o aplicativo de celular "Sound Meter", nesse ponto temos uma questáo importante que é o uso da tecnologia do celular para o ensino. Foram realizados procedimentos de calibraçáo e medidas ao longo de um dia inteiro de aulas com os alunos subdivididos em grupos realizando as medidas com os seus celulares sem interromper o fluxo natural das aulas. Os dados médios de intensidade sonora indicam que a intensidade sonora é mais elevada no primeiro período e vai decrescendo até o terceiro período, no intervalo/recreio é aonde se registra um maior nível de intensidade sonora e o quarto período de volta do recreio possui um nivel de intensidade sonora um pouco mais elevado em relaçáo ao primeiro periodo demontrando que a turma demora um pouco a se acalmar até o quinto período. $O$ segundo e o terceiro período 
registraram os valores médios mais baixos de intensidade sonora. Considerando a escala de intensidade sonora do aplicativo "Sound Meter" esses níveis de ruído estão entre "conversação normal" (60dB) e o "tráfego local" (70dB). De acordo com a a NBR 10.152/1987 que fixa valores de intensidade sonora adequadas para o ambiente escolar, deve-se ter os seguintes níveis nos espaços escolares: (i) 34-45 dB nas bibliotecas; (ii) 40-50 dB nas salas de aula e laboratórios; e (iii) 45-55 dB nos ambientes de circulação. Os valores encontrados para o ambiente de sala de aula e no intervalo/recreio demonstraram-se um pouco mais elevados do que os aceitáveis. Essa atividade com o uso do celular, que em geral é proibido durante as aulas, trouxe uma motivaçáo extra aos estudantes para o desenvolvimento das mediçóes e verificação das intensidades sonoras no espaço escolar.

Estratégias de ensino contextualizadas permitem aos estudantes vislumbrar os conhecimentos científicos no seu dia-a-dia; e por sua vez o desenvolvimento de atividades práticas permitem uma maior interatividade do aluno no processo de ensino-aprendizagem. $\mathrm{O}$ avanço e o acesso às tecnologias digitais no mundo atual torna imprescindível e urgente a inserção dessas ferramentas no ensino, possibilitando formas de aprender mais atraente e motivadoras para os estudantes; ressignificando o uso de dispositivos como o caso do celular, que além de possibilitar comunicação e entreterimento, possa também ter seu papel educacional.

\section{Referências}

ASSOCIAÇÃO BRASILEIRA DE NORMAS TÉCNICAS. NBR 10.151: Acústica: Avaliação do ruído e áreas habitadas, visando o conforto da comunidade: procedimento. Rio de Janeiro, 2000. Disponível em: <http://www.sema.df.gov.br/wp- conteudo/ uploads/2017/09/NBR-10151-de-2000.pdf>. Acesso em: 8 fev. 2020.

ASSOCIAÇÃO BRASILEIRA DE NORMAS TÉCNICAS. NBR 10.152: níveis de ruído para conforto acústico. Rio de Janeiro, 1987. Disponível em : <http://www.joaopessoa. pb.gov.br/portal/wp-content/uploads/2015/02/NBR_10152-1987-Conforto-Ac_stico. pdf>. Acesso em: 8 fev. 2020.

BARCELOS, Daniela Dalapicula; DAZZI, Natália Saliba. Efeitos do mp3 player na audição. Rev CEFAC, v. 16, n. 3, p. 779-91, 2014. Disponível em: <http://www.scielo.br/ pdf/rcefac/v16n3/1982-0216-rcefac-16-3-0779>. Acesso em: 20 de fev. de 2020.

BRASIL. Base Nacional Comum Curricular (BNCC). Ministério da Educação. Brasília. 2017. Disponível em: <http://basenacionalcomum.mec.gov.br/images/BNCC_EI_ EF_110518_versaofinal_site.pdf>. Acesso em: 7 de fev. de 2020.

BRASIL. Resolução CONAMA 001, de 08 de março de 1990. Conselho Nacional de Meio Ambiente. Disponível em: <http://www2.mma.gov.br/port/conama/legiabre. cfm?codlegi=98>. Acesso em: 7 de fev. 2020. 
BRASIL. Resolução CONAMA 002, de 08 de março de 1990. Conselho Nacional de Meio Ambiente. Disponível em: <http://www2.mma.gov.br/port/conama/legiabre. cfm?codlegi=99>. Acesso em: 8 de fev. 2020.

BRASIL. Resolução CONAMA 272, de 14 de setembro de 2000. Conselho Nacional de Meio Ambiente. Disponível em: <http://www2.mma.gov.br/port/conama/legiabre. cfm?codlegi=270>. Acesso em: 8 de fev. 2020.

BRESSANE, Adriano; SANTARINE, Gerson Antonio; MAURÍCIO, Júnior Cintra. Poluição Sonora: síntese de princípios fundamentais da teoria acústica. Holos Environment, v. 10, n. 2, p. 223-237, 2010.Disponível em: <https:/www.cea- unesp.org. br/holos/article/view/4728>. Acesso em: 7 de fev. 2020.

LACERDA, ABM de et al. Hábitos auditivos e comportamento de adolescentes diante das atividades de lazer ruidosas. Rev Cefac, v. 13, n. 2, p. 322-9, 2011.

MINISTÉRIO DO TRABALHO - Norma Regulamentadora no 15 Anexo 1 - Limites de Tolerância para Ruído Contínuo ou Intermitente, 1997. Disponível em: <http:// trabalho.gov.br/images/Documentos/SST/NR/NR15/NR15-ANEXO1.pdf>. Acesso em: 8 fev. 2020.

PALACIOS, J.O.G; MARQUEZE, E.C. Efeitos nocivos ao sistema auditivo provocados por escutas em aparelhos de sons portáteis e computadores em altos níveis de pressão sonora. In: Anais SULCOMP,vol. 2, 2006. Disponível em: <http://periodicos.unesc.net/ sulcomp/article/view/939/913>. Acesso em 10 mar. 2020.

SILVA, I. S. Categorização de aplicativos educacionais em dispositivos móveis: um olhar sobre a produção para o ensino de Ciências Naturais. 2018. Disponível em <https:// rosario.ufma.br/jspui/bitstream/123456789/2723/1/IsaiasSilva.pdf>. Acesso em: 20 mar. de 2020 .

TOMÉ, D., CAEIRO, A., CASTRO, F., NETO, C., SANTOS, T., LOPES, P. (2018). Efeitos do ruído na audição, Rev. Ciência Elem., V6(04):083. doi.org/10.24927/ rce2018.083. Disponível em: <https://recipp.ipp.pt/bitstream/10400.22/13938/1/ART_ DavidTom\%c3\%a9_2018.p df>. Acesso em: 20 de fev. de 2020.

TRAVERSI, G.S., MANZKE, V.H.B., SEIXAS, R.H.M. Concepçóes de um grupo de professores de ciências de escolas públicas de Pelotas/RS sobre ensino experimental. Revista Educar Mais, v.3, n.1, p. 69-78, 2019.

USBERCO, J.; MARTINS, J.; SCHECHTMANN, E.; FERRER, L. C.; VELLOSO, H. Companhia das ciências, $9^{\circ}$ ano. 4. ed. São Paulo: Saraiva, 2015. 304p.

ZOCOLLI, A. M. F.; MORATA, T.; MARQUES, J.. Adaptação para o português brasileiro do questionário: Youth Attitude to noise scale (YANS). Brazilian Journal of Otorhinolaryngology, v. 75, n. 4, p. 485-492, 2009. 